\title{
Solar-Powered Photocatalytic Fiber-Optic Cable Reactor for Waste Stream Remediation
}

N. J. Peill

M. R. Hoffmann ${ }^{1}$

Environmental Engineering Science

W. M. Keck Laboratories California Institute of Technology, Pasadena, CA 91125
The design and testing of a solar-powered fiber-optic cable reactor prototype for the photocatalytic destruction of organic pollutants is presented. A concentrating collector directs sunlight into a fiber-optic cable which transmits light to a $\mathrm{TiO}_{2}$ photocatalyst immobilized on the fibers and immersed in a reaction solution. The performance of the reactor using solar and artificial UV radiation are compared. The system is also compared to another fiber-optic cable reactor having a 50 percent higher photocatalytic surface area-to-reactor volume ratio to investigate mass transport limitations. Reaction rates for the oxidation of 4-chlorophenol of 25 and $12 \mu \mathrm{M}$ min $^{-1}$ were measured for solar and artificial UV sources, respectively. The faster reaction rate using solar radiation is due to a higher UV light flux compared to the artificial source. Both fiber-optic reactor systems were determined not to be mass transport limited. Relative quantum efficiencies of $\phi=0.014$ and $\phi=0.020$ were determined for the solar and artificial irradiations, respectively. In agreement with previous findings, enhanced quantum efficiencies are attributed to a lower absorbed light intensity-to-photocatalytic surface area ratio. The solar reactor prototype was found to degrade effectively 4-chlorophenol and may prove useful for the in situ passive decontamination of subsurface and other remote environments.

\section{Introduction}

The capability of metal oxide semiconductor photocatalysts to degrade effectively a wide range of hydrocarbon contaminants has been well documented (Matthews, 1990; Fox and Dulay, 1993; Mills et al., 1993; Ollis and Al-Ekabi, 1993; Hoffmann et al., 1995). The solid photocatalyst is activated by ultraviolet light generating holes and excited electrons which combine with surface sorbed species such as water and oxygen to form highly reactive radical species (e.g., $\mathrm{OH} \cdot$ and $\mathrm{O}_{2}^{-}$). These radical intermediates nonselectively oxidize organic pollutants such as chlorinated hydrocarbons, pesticides, solvents, and aromatic compounds in most cases yielding only carbon dioxide, water, and dilute mineral acids (e.g., $\mathrm{HCl}$ ) as the final products.

Many studies have addressed the immobilization of a photocatalyst in a practical fixed-bed reactor configuration that allows for the continuous use of a photocatalyst without the need for post-process filtration (Al-Ekabi and Serpone, 1988; Bellobono et al., 1992; Yamazaki-Nishida et al., 1993; Zeltner et al., 1993; Bellobono et al., 1994; Hofstadler et al., 1994; Sauer and Ollis, 1994). Furthermore, several commercial photocatalytic reactor systems have been developed for aqueous and gas-phase waste treatment (Xu et al., 1988; Al-Ekabi et al., 1991; Suzuki, 1993). However, the photocatalytic process has been criticized as being uneconomical compared to other oxidative treatment systems due to its low photochemical conversion efficiencies that may result in higher overall energy costs (Renner, 1996; Wilson, 1996).

However, there is a growing body of laboratory and field studies which suggests that the use of solar radiation to power photocatalytic reactor systems may lead to more economical treatment alternatives for certain applications (Matthews, 1987; Bockelman et al., 1993; Mehos and Turchi, 1993; Minero et

\footnotetext{
'To whom correspondence should be addressed.

Contributed by the Solar Energy Division of THE AMERICAN SOCIETY OF MECHANICAL ENGINEERS for publication in the ASME JouRnal of Solar ENERGY ENGINEERING. Manuscript received by the ASME Solar Energy Division, Oct. 1996; final revision, Jan, 1997. Associate Technical Editor: D. M. Blake.
}

al.; 1993; Pacheco et al., 1993; Zhang et al., 1993; Muradov, 1994; Wyness et al., 1994; Wyness et al., 1994; Zhang et al., 1994; Pugh et al., 1995; Crittenden et al., 1996; Zhang et al., 1996). The solar spectrum consists of about six percent UV radiation which is useful for photocatalyst activation $(\lambda<380$ $\mathrm{nm})$. Sensitization of a photocatalyst can extend the useful spectrum into the visible region (Dieckmann et al., 1993; Dieckmann and Gray, 1996). Solar-powered systems can be either nonconcentrating or concentrating. Nonconcentrating systems utilize direct and diffuse sunlight enabling operation in overcast and hazy conditions but are limited to the UV energy flux of one sun, $\sim 40 \mathrm{Wm}^{-2}$. Concentrating systems generally require the use of a tracking device but can employ much greater UV energy fluxes resulting in higher processing capacities and/or smaller systems.

Solar-driven reactor systems involving shallow ponds, parabolic troughs, flat plates, glass fibers, and fiberglass mesh have been investigated previously (Minero et al., 1993; Zhang 1993; Bauer, 1994; Muradov, 1994; Wyness et al., 1994; Wyness et al., 1994; Zhang et al., 1994; Pugh et al., 1995; Crittenden et al., 1996; Zhang et al., 1996), In contrast to this previous work, we employ a bundled array of optical fibers to transmit light to a photocatalyst immobilized on the fibers and immersed in a reaction solution. This configuration has several advantages over conventional fixed-bed reactor designs (Peill and Hoffmann, 1995; Peill and Hoffmann, 1996). Immobilization of the photocatalyst on the fibers enhances the spacial uniformity and distribution of the activated photocatalyst in the reaction solution volume. Direct delivery of light to the photocatalyst minimizes radiation losses due to scattering and absorption by the reactor and reaction solution. Transmission of light to the photocatalyst via the fiber-optic cable allows for treatment of remote environments.

A potential advantage of the optical-fiber reactor (OFR) is that it can operate in a high quantum efficiency domain characteristic of low incident light intensities while maintaining high reaction rates by employing high input light intensities (Ollis et al., 1991). This combination is achieved by employing a large number of fibers and distributing the photon flux over a 
large photocatalytic surface area. In this paper, we discuss the design of a solar OFR2 prototype and compare its performance using solar and artificial radiation for the photocatalytic oxidation of 4-chlorophenol. We also compare the OFR2 with the performance of a previous prototype, OFR1, having a 50 percent higher photocatalytic surface area.

\section{Experimental Section}

Optical-Fiber Reactor (OFR2). An optical-fiber bundled array reactor was constructed based on a previous design (OFR1) which is described in detail elsewhere (Peill and Hoffmann, 1995). A schematic diagram of the optical-fiber photocatalytic reactor system is shown in Fig. 1. The reactor system consists of a light source, a coated fiber-optic bundle and a reaction vessel. A $1000 \mathrm{~W}$ Xe arc lamp (Oriel 6295) provided UV radiation for the indoor experiments. Outdoor experiments were conducted on the roof of Keck Laboratory building at Caltech in Pasadena, CA. Light is focused into the bundle and transmitted through the fibers using a quartz focusing lens (Rolyn Optics) for the artificial light source or a concentrating compound reflector device (vide infra) for sunlight collection. The fiber bundle consists of $5731-\mathrm{mm}$ diameter, $1.3 \mathrm{~m}$ long quartz optical fibers (3M Power-Core FT-1.0-UMT). A 30-cm length of the fibers was stripped to expose the quartz core. The stripped fibers were then threaded through two perforated Teflon plates that serve as a fiber spacer and lid for the reactor at a spacing of $3.0 \mathrm{~mm}$ center to center. The prepared fibers were bundled and polished by Fiberoptic Systems, Inc., Simi Valley, CA. After bundling, the stripped portion of the fibers were coated with a 15 wt\% aqueous suspension of $\mathrm{TiO}_{2}$ (Degussa P25) and allowed to air dry for $24 \mathrm{~h}$. The $4.2 \mathrm{~L}(32 \times 13 \mathrm{~cm}$ diameter) cylindrical reactor vessel was constructed from Pyrex with a bottom glass frit (fine) and gas inlet for the introduction of air or oxygen for oxygenation and mixing of the reaction solution $\left(\sim 2 \mathrm{ml} \mathrm{min}^{-1}\right)$. Sample ports and a temperature port are located at the top and bottom of the vessel and are fitted with Teflon-coated septum screw caps. The dual lid and fiber spacer is constructed from Teflon with a $2 \mathrm{~mm}$-deep groove to fit over the reactor vessel. The hole spacings are concentrically arranged at a spacing of $3.0 \mathrm{~mm}$ center to center. The fiber bundled array fits coaxially into the reactor vessel.

Solar Collector Device. The solar collector device shown in the photo in Fig. 2, along with the equatorial tracker and reaction vessel, consists of an equatorial tracking mount and

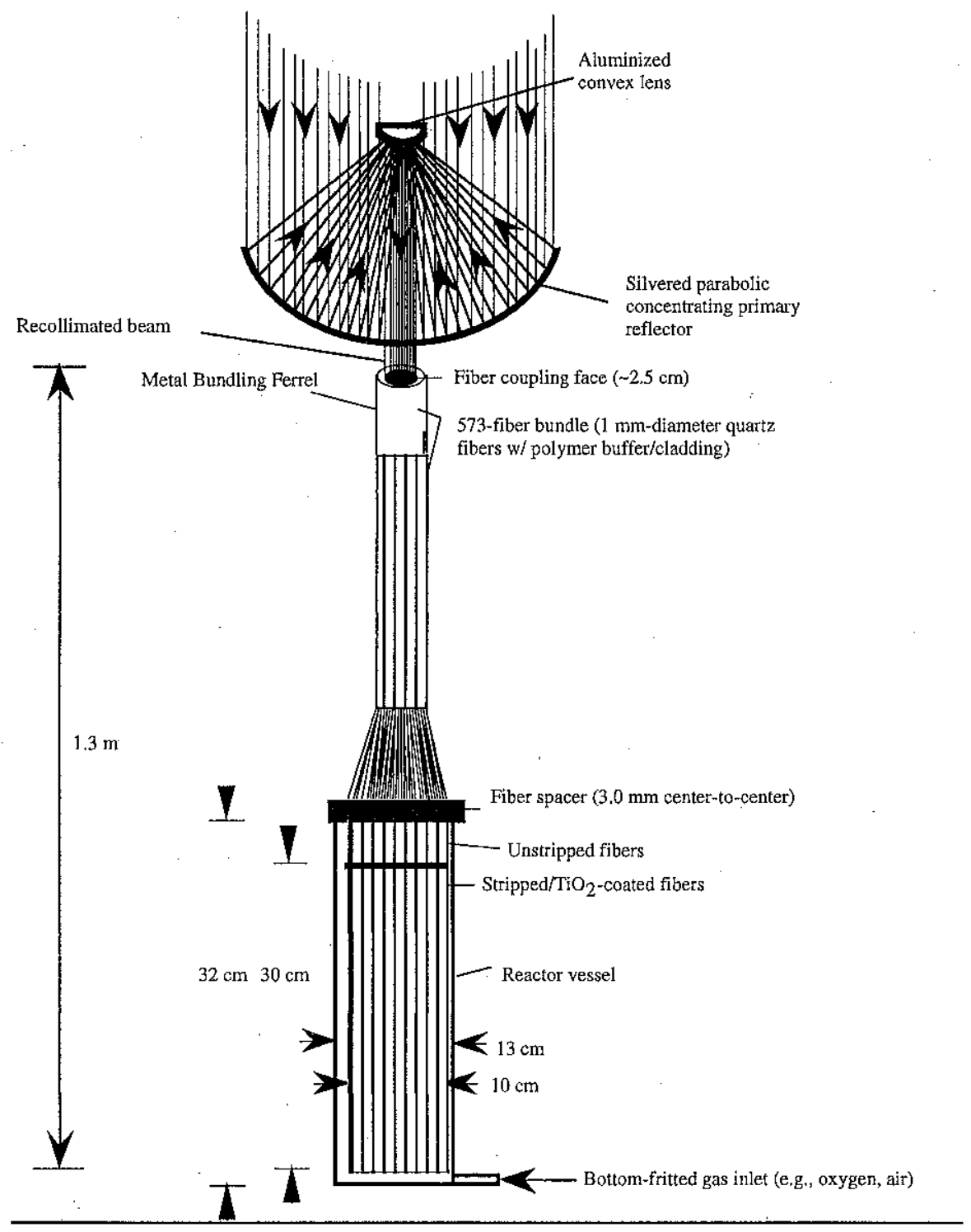

Fig. 1 Schematic of OFR2 with solar collector/concentrator. Equatorial tracker not shown. 




Fig. 2 Photograph of OFR2 on Keck Laboratory roof complete with reactor vessel, solar collector, and equatorial tracker

gearing, and a compound reflector. The compound reflector arrangement concentrates and directs sunlight into the fiberoptic cable reactor. The bottom primary reflector is a 24-in. diameter silvered (concave side) parabolic glass dish (Baush and Lomb) with an eight-inch focal point. A thin acrylic lacquer coating (DCA 468 clear, PPG Industries, 8:1 mix with lacquer thinner) prevents oxidation of the silver coating (Peacock Laboratories). An aluminized 3.5-in. diameter convex lens (PCX Rolyn Optics) serves as the secondary reflector. The aluminum coating is protected with a magnesium fluoride UV-transparent coating. The secondary reflector is positioned in front of the focal point of the primary reflector to achieve a beam spot size approximately 75 percent of the coupling face diameter, e.g., 0.75 in

The compound reflector is supported by an aluminum equatorial tracking mount and tilted at a 34 deg angle (average solar zenith angle for Los Angeles, CA). After aligning the compound refiector with the sun, it is rotated by a geared (1444:1) synchronous motor at $15 \mathrm{deg} \mathrm{hr}^{-1}$.

Light Flux Determination. Input light intensities into the fiber bundle, $I_{\text {input }}$, for the solar and artificial sources were measured by chemical actinometry using ferrioxalate $(\mathrm{FeOx})$ according to the method by Calvert and Pitts' (Calvert and Pitts, 1966). In general, a $1 \mathrm{~L} 0.006 \mathrm{M}$ solution of reagent grade potassium ferrioxalate (Pfaltz \& Bauer) acidified in $0.1 \mathrm{M}$ $\mathrm{H}_{2} \mathrm{SO}_{4}$ (Baker, $\mathrm{AR}$ ) is irradiated at 10 -second intervals. At each interval a $10 \mathrm{~mL}$ aliquot is taken and diluted to $25 \mathrm{~mL}$ with 2 $\mathrm{mL}$ of a $0.1 \mathrm{wt} \%$ solution of 1,10 -phenanthroline (Baker, AR), $5 \mathrm{~mL}$ of a $1.0 \mathrm{~N}$ sodium acetate (EM Science, GR) buffer, and $8 \mathrm{~mL}$ of deionized water (Milli-Q). After standing for one hour the absorbence of each sample solution is taken at $\lambda=510 \mathrm{~nm}$. The tip of the uncoated bundle was immersed in the actinometry solution and irradiated using either sunlight or artificial light. A series of measurements was made and averaged. An outdoor input flux measurement was also made subsequent to coating the fiber bundle. Outdoor measurements were made at 12:00 hours.

The ambient solar flux as a function of wavelength and time of day was also measured using a spectral radiometer (LI-COR Li-1800). The absorbed light intensity, $I_{a b s}$, of the coated bundle was assumed to be 95 percent of the input light intensity based on previous findings (Peill and Hoffmann, 1995, 1996).

Photooxidation of 4-chlorophenol. A $4.0 \mathrm{~L}, 0.10 \mathrm{mM}$ solution of 4-chlorophenol (4CP) was prepared from a $1.0 \mathrm{mM}$ stock solution (Aldrich, $99+$ percent). Before irradiation, the coated-fiber bundle was immersed in the reaction solution and allowed to equilibrate for 30 minutes. The irradiations were carried out until the complete disappearance of 4CP was observed. This required two days of irradiation for the outdoor experiment from 10:00 to 17:00 hours each day. Nylon (Nalgene $0.45 \mu \mathrm{m})$ syringe filters were used to filter all samples. 4CP was analyzed by HPLC (HP SeriesII 1090) using a Hewlett Packard ODS Hypersil $(5 \mu \mathrm{m})$ column with an eluent $(1 \mathrm{~mL}-$ $\mathrm{min}^{-1}$ ) of $20 / 80$ percent acetonitrile/water $(\mathrm{pH} \mathrm{3})$. UV absorbence was measured at 224 and $250 \mathrm{~nm}$. Chloride-ion production was quantified using a chloride ion selective electrode (Orion $9617 \mathrm{BN}$ ) or by ion chromatography (Dionex BIOLC $4500 \mathrm{i}$ series) using an Ionpac AG11 Guard column with an eluent $\left(1 \mathrm{~mL}-\mathrm{min}^{-1}\right)$ of $75 / 25$ percent $5 \mathrm{mM} / 100 \mathrm{mM} \mathrm{NaOH}$. The $\mathrm{pH}$ was determined with a Radiometer PHM85 $\mathrm{pH}$ meter.

\section{Results}

Ambient solar flux data from the roof of the Keck Laboratory building were used to size the solar concentrator shown in Fig. 2. Figures $3(a)$ and $(b)$ show representative flux data taken with the spectral radiometer as a function of wavelength at 1330 $\mathrm{h}$ and time of day, respectively. The UV flux ( $300 \leq \lambda \leq 380)$ reaches a maximum at $380 \mathrm{~nm}$ of $2 \mathrm{~W} / \mathrm{m}^{2}$-nm which is less than one-third of the total spectral maximum. The integrated UV flux ranges from 45 to $90 \mathrm{~W}-\mathrm{m}^{-2}\left(0.88-1.84 \mu \mathrm{E} \mathrm{min}^{-1}\right.$

(a)
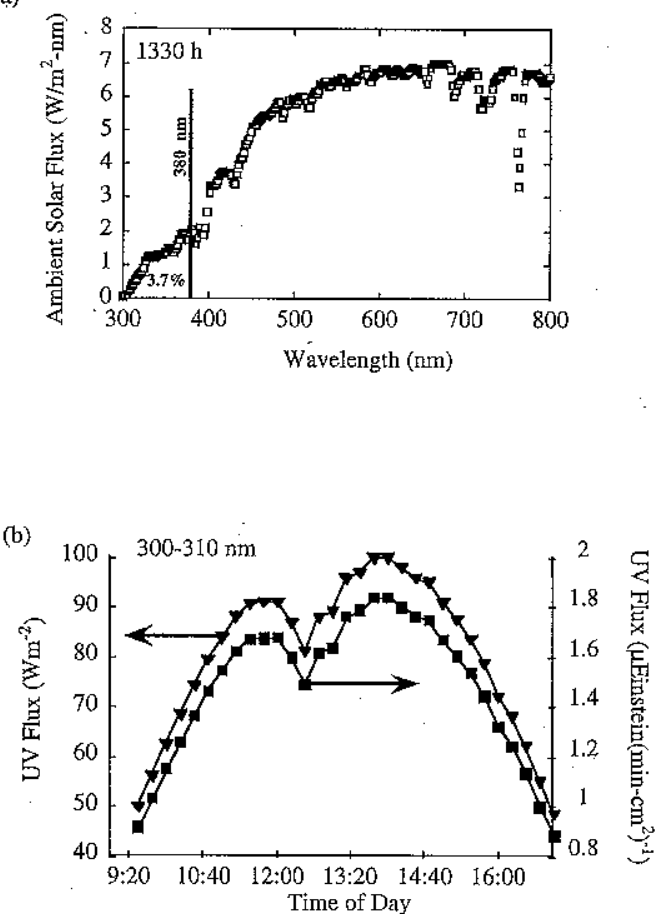

Fig. 3 Representative solar flux as a function of (a) wavelength taken at $1330 \mathrm{~h}$ and $(b)$ time of day measured by spectral radiometer during July 1996 
$\mathrm{cm}^{-2}$ ) reaching a maximum at 14:00 hours. This UV flux represents about 3.7 percent of the total ambient solar flux.

Due to irregularities in the surface of the primary reflector, only the inner 17 -in. radius of the reflector was useful for solar collection, representing about $1400 \mathrm{~cm}^{2}$ of reflective surface area. Since the fiber bundle coupling face consists of $4.5 \mathrm{~cm}^{2}$ of fiber area, this gives a concentration factor of approximately 300. A total theoretical (without losses) concentrated UV flux

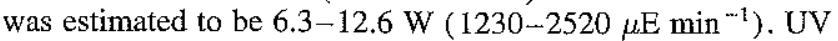
reflectivity losses of about 45 percent for the silver/lacquer coating and an overall beam-to-bundle coupling efficiency of 80 percent were estimated.

Actinometric flux measurements were carried out to determine the input light intensity into the OFR2. Total fluxes of 68 \pm 11 and $360 \pm 15 \mu \mathrm{E} \mathrm{m^{-1 }}$ were measured for the artificial and solar light sources, respectively. UV fluxes were calculated to be 40 percent and 50 percent, respectively, of the total measured flux based on the Xe arc lamp output and solar spectrums and the wavelength dependency of the ferrioxalate measurement. The measured flux of the coated fiber bundle was negligible, less than five percent of the uncoated bundle flux, indicating that most of the input UV light was being absorbed by the coating. The non-UV wavelengths would have passed through the coating.

4-chlorophenol was chosen as a model pollutant for its low volatility and moderate solubility. $4 \mathrm{CP}$ has been reported to undergo hydroxyl radical insertion as an initial step in the overall oxidation (Al-Sayyed et al., 1991; Tseng and Huang, 1991; Mills and Hoffmann, 1993) according to the following generally accepted mechanism (Choi and Hoffmann, 1995; Hoffmann et al., 1995):

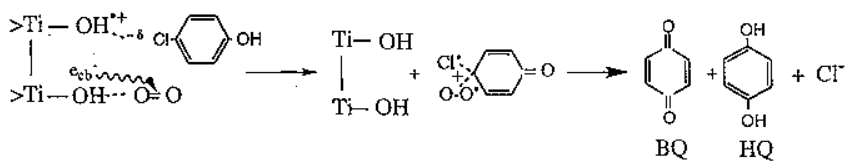

A controlled indoor irradiation experiment was carried out to compare the performance of the OFR2 using solar radiation for the oxidation of 4CP. In addition, these results are compared to $4 \mathrm{CP}$ oxidation experiments carried out using OFR1 (Peill and Hoffmann, 1995, 1996). The initial reaction rates, time to "complete degradation" ([4-CP $\left.]_{\text {final }} \approx 0.01[4-\mathrm{CP}]_{o}\right)$, and the relative quantum efficiencies are summarized in Table 1 . The higher initial reaction rate and faster time to complete degradation for the OFR2 outdoor experiment is due to the higher absorbed light intensity, 25-41, compared to $10 \mu \mathrm{E} \mathrm{L}^{-1} \mathrm{~min}^{-1}$. The OFR2 performed comparably to the OFR1 but achieved higher relative quantum efficiencies for both the indoor and outdoor irradiations. A relative quantum efficiency of $\phi=0.020$ was achieved for the indoor OFR2 experiment which is comparable to previously reported values for the photocatalytic oxidation of 4CP (Barbeni et al., 1985; Al-Sayyed 1991; Mills and Hoffmann, 1993; Hofstadler, 1994).

Table 1 4CP oxidation reaction summary carried out in the OFR1 indoor and the OFR2 indoor and outdoor. Experimental conditions for the OFR1 and OFR2 oxidations are the same except for $I_{\text {abs }}$ (shown in table) and the reaction solution volume, 0.19 and $4 \mathrm{~L}$, respectively.

\begin{tabular}{|l|c|c|c|c|c|c|}
\hline $\begin{array}{c}\text { 4CP } \\
\text { Oxidation } \\
\text { Experiment }\end{array}$ & $\begin{array}{c}\mathbf{I}_{\mathbf{a b s}} \\
\left(\mu \mathrm{E} \mathrm{L} \mathbf{L}^{-1}\right. \\
\left.\mathbf{m i n}^{-1}\right)\end{array}$ & $\begin{array}{c}\text { Initial } \\
\text { Reaction } \\
\text { Rate } \\
(\mu \mathrm{M} / \mathbf{h r})\end{array}$ & $\begin{array}{c}\mathbf{t}_{1 / 2} \\
(\mathbf{h r})\end{array}$ & $\begin{array}{c}\text { Time to } \\
\text { Complete } \\
\text { Degradati } \\
\text { on } \\
(\mathbf{h r})\end{array}$ & $\begin{array}{c}\mathbf{I}_{\text {abs }} / \text { surface } \\
\text { area } \\
(\mu \mathbf{E ~ L - 1} \\
\left.\mathbf{m i n}^{-1} \mathbf{m}^{-2}\right)\end{array}$ & $\phi$ \\
\hline \hline OFR2 Indoor & 10 & 12 & 5.0 & 16 & 0.2 & 0.020 \\
\hline OFR2 Outdoor & 30 & 25 & 3.5 & 13 & 0.5 & 0.014 \\
\hline OFR1 & 22 & 15.5 & 4.5 & 13 & 5.0 & 0.012 \\
\hline OFR1 & 31 & 17.5 & 3.5 & 13 & 7.0 & 0.009 \\
\hline
\end{tabular}

The results of the 4CP oxidations using artificial and solar light are summarized in Table 1 . Initial reaction rates of 12.0 and $25.0 \mu \mathrm{M} / \mathrm{hr}, t_{1 / 2}$ of 5.0 and 3.5 hours were measured, respectively. A two order-of-magnitude reduction in $4 \mathrm{CP}$ was achieved after 16 and 13 hours of irradiation, respectively. Stoichiometric production of chloride was observed in both cases. A relative quantum efficiency for the indoor irradiation of $\phi=$ 0.020 was determined where $\phi$ is defined as

$$
\phi=\frac{\frac{d[4 \mathrm{CP}]}{d t}}{\frac{d[h \nu]_{\mathrm{abs}}}{d t}} \cong \frac{\text { initial rate }}{\text { absorbed flux }} .
$$

A relative quantum efficiency range for the outdoor irradiation of $\phi=0.017-0.010$ was estimated based on an average UV flux of $30 \pm 5 \mu \mathrm{E} \mathrm{min}^{-1}$ for the one-hour irradiation period.

\section{Discussion}

The need for low-cost novel technologies for the decontamination of subsurface water and other waste streams has spurred the development of solar-powered photocatalytic reactors which combine cheap and environmentally benign photocatalysts such as $\mathrm{TiO}_{2}$ and sunlight. A unique feature of the OFR is the remote delivery of light to a photocatalyst allowing for in situ treatment of a contaminated site. This would eliminate the need to pump contaminated water to the surface for treatment required for most other treatment technologies. The OFR, as a fixed-bed reactor, is also ammenable to gas-phase operation. Photocatalytic reaction in the gas phase has been shown to be substantially faster than in the aqueous phase (Dibble and Raupp, 1990; Nimlos et al., 1993; Yamazaki-Nishida et al., 1993). Additionally, the use of sunlight as the UV source would further reduce treatment costs. In advanced oxidation systems, the UV radiation supply typically represents a large fraction of the capital and operating costs (Miller and Fox, 1993; Bolton et al., 1995). The primary objective of the present work is to demonstrate the feasibility of utilizing solar radiation in an OFR for the destruction of hydrocarbon pollutants.

Reactor Design. Critical design features of the OFR2 in clude: the reaction solution volume, the total UV flux, and the fiber bundle size. A batch volume of $4 \mathrm{~L}$ was chosen for this project which is 20 times larger than the OFR1 design. OFR1 studies suggested that a minimum input UV flux of $50 \mu \mathrm{E}$ ( $\mathrm{L}$ min $)^{-1}$, assuming $\sim 100$ percent absorption by the coating, was necessary to achieve the complete oxidation of 4CP in one day (six hours) of irradiation (Peill and Hoffmann, 1996). Thus, the minimum total input UV flux desired was $200 \mu \mathrm{E} \mathrm{min}{ }^{-1}$. An estimated photocatalytic coating surface area-to-reaction volume ratio of $23.3 \mathrm{~m}^{2} \mathrm{~L}^{-1}$ employed in the OFR1, which consisted of $72,20 \mathrm{~cm}$ long coated fibers in a single bundle, was used as a base parameter to size the fiber bundle (Peill and Hoffmann, 1996). Single-fiber light distribution experiments with 13 wt\% Degussa P25 revealed that collimated light is propagated $35 \mathrm{~cm}$ before being completely absorbed by the photocatalytic coating. Therefore, coated fiber lengths of $30 \mathrm{~cm}$ were used to maximize the activated photocatalytic surface area. The fibers at the reaction end of the bundle were spaced $2 \mathrm{~mm}$ apart in a concentric, parallel arrangement to ensure a uniform distribution of the photocatalyst within the reaction volume. Assuming a coating thickness and porosity of $6 \mu \mathrm{m}$ and 0.9 (Peill and Hoffmann, 1995, 1996) and a photocatalyst density and specific surface area of $3.9 \mathrm{gcm}^{-3}$ and $50 \mathrm{~m}^{2} \mathrm{~g}^{-1}$ (Degussa, 1990), respectively, a fiber bundle consisting of 573 one-mm diameter fibers gave a photocatalytic surface area-to-reaction volume ratio that was 68 percent of the OFR 1 . This ratio was deemed sufficiently different to be able to investigate also possible mass transport effects. 
Three alternative solar collector designs were considered. They involved the use of (1) a compound Fresnel lens arrangement, (2) a combination Fresnel film and lens arrangement, as illustrated in Fig. 4, and (3) a compound parabolic reflector arrangement. The first option consists of a UV-transmitting quartz lens of sufficient collection diameter (e.g., $30 \mathrm{~cm}$ ) coupled with a secondary quartz lens to collimate the concentrated light. The primary lens was not commercially available and was determined to be cost prohibitive. The Fresnel film is manufactured by $3 \mathrm{M}$ for photovoltaic systems and consists of a continuous web of non-UV transmitting acrylic $(0.6 \mathrm{~mm}$ thick) with prisms on one side and a smooth surface on the other. The thin film is bonded to a rigid sheet such as UV-transmitting acrylic for support. The concentrated light is collimated and coupled with the bundle using a secondary quartz lens. However, this alternative configuration was rejected because the quantity of film required $\left(\sim 350 \mathrm{~cm}^{2}\right)$ was not sufficient to cover the commercial development costs and the development time (i.e., greater than six months) was extensive. In addition, unless UV transmitting substitutes could be developed, the acrylic lens film and bonding material would absorb some portion of the UV flux. This arrangement, however, might prove to be a superior alternative for future consideration as it is simple, light weight, and can probably be constructed of UV transmitting film. The third option consists of a bottom primary parabolic reflector coupled with a secondary upper reflector that is positioned in front of (convex) or behind (concave) the focal point of the primary reflector. The secondary reflector is adjusted until a

(a)



(b)

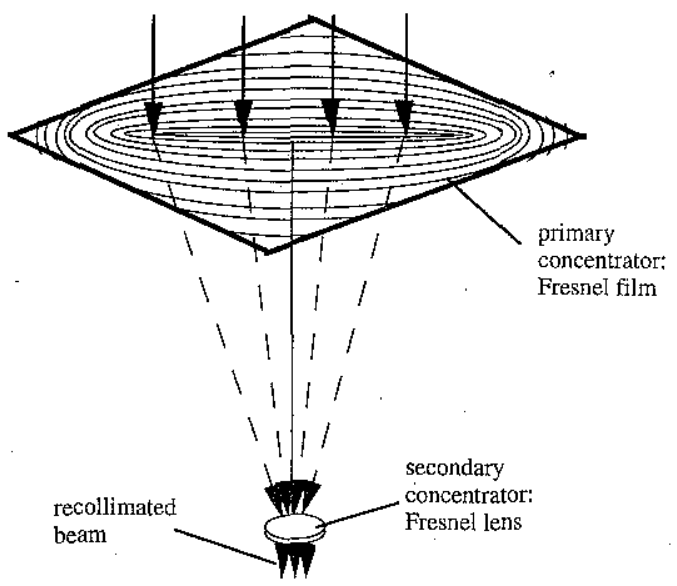

Fig. 4 Alternative solar collector arrangements: (a) a large-diameter quartz Fresnel lens coupled with a smaller quartz Fresnel lens and $(b)$ Fresnel film coupled with a quartz Fresnel lens to recollimate the light

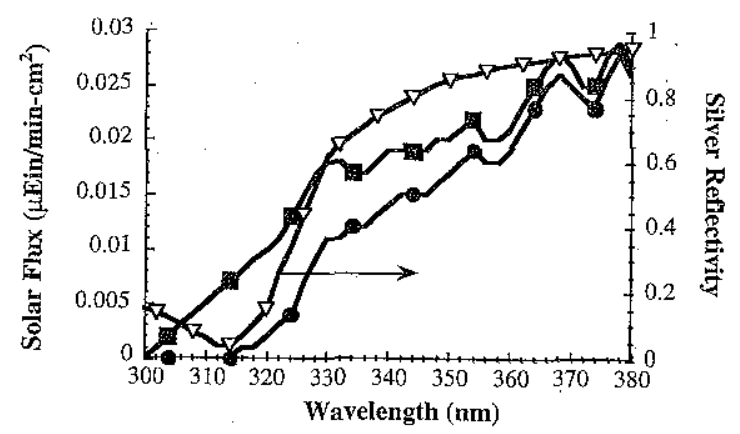

Fig. 5 The (B) ambient and (J) mitigated UV flux due to the incomplete reflectivity of the silver coating $(\mathrm{S})$ are plotted as a function of wavelength

collimated beam is achieved coupling the light with the fiber bundle face. This arrangement was chosen for its simplicity and availability of parts.

The primary collector diameter was set based on the desired input flux, $I_{\text {input }}$, the ambient solar flux data, $I_{\text {ambient }}$, (Fig. 3) and the estimated efficiencies for the primary, $\eta_{\text {primary }}$, and secondary, $\eta_{\text {secondary }}$, reflectors and the beam-to-bundle coupling efficiency, $\eta_{\text {couple }}$ :

$$
d_{\text {primary }}=\left\{\frac{4 * I_{\text {inpul }}}{\pi * I_{\text {ambient }} * \eta_{\text {primary }} * \eta_{\text {secondary }} * \eta_{\text {couple }}}\right\}^{1 / 2} .
$$

Figure 5 is a plot of silver reflectivity data as a function of wavelength, the ambient solar flux, and the corresponding reduction of the reflected solar flux (Holland, 1958). The reflectivity at each wavelength was weighted by the contribution of the wavelength to the ambient UV flux and integrated. This resulted in an estimated reflection efficiency for the silver coating of 75 percent. Spectral analysis of the lacquer coating used to protect the silver coating indicated a UV transmittance of about 60 percent. Thus, the overall reflection efficiency for the primary reflector was estimated to be $\eta_{\text {primary }}=45$ percent. The aluminum coating on the secondary reflector was estimated to have a reflection efficiency of $\eta_{\text {sccondary }} \approx 100$ percent (Holland, 1958). Three main factors affected the beam to fiber coupling efficiency. They were (1) the input beam angle, (2) the beam spot size relative to the fiber core diameter, and (3) Fresnel losses due to refraction. The input beam angle should be within 80 percent of the acceptance angle, $\theta$, given by

$$
\theta=\operatorname{ArcSin}\left\{\gamma^{*}\left(n_{1}^{2}-n_{2}^{2}\right)^{1 / 2}\right\}
$$

where $\gamma$ is the numerical aperture of the fiber core and $n_{1}$ and $n_{2}$ are the refractive indices of the fiber core and ambient medium (e.g., air, $n_{2}=1.0$ ), respectively. A fiber bundle consisting of $3 \mathrm{M} \mathrm{Ft}-1.0 \mathrm{UMT}$ fibers has a $\gamma$ of 0.3 and a fiber core refractive index of 1.413. These values give an acceptance angle of 17 deg. Therefore, the beam should be incident on the fiber coupling face at an angle less than 14 deg with respect to the axis of the fiber for efficient coupling. The beam spot size should be 80 percent of the core diameter (e.g., $8 \mathrm{~mm}$ ). Some losses may occur if this criterion is not achieved since the reflected beam diameter spans the entire fiber bundle coupling face. Fresnel losses of about four percent due to refraction of the beam off the bundle face may also be incurred. Due to a fiber packing factor that is close to 0.9 (i.e., hexogonal close packing cross section), there is a ten percent coupling loss due to void space in the bundle coupling face. Overall, a coupling efficiency, $\eta_{\text {coupling, }}$, was conservatively estimated to be 80 percent and, thus the overall solar collection/coupling efficiency is reduced to 36 percent.

Ambient UV fluxes ranged from 0.88 to $1.84 \mu \mathrm{E} \mathrm{min}^{-1} \mathrm{~cm}^{-2}$ during the summer months. Using these values in Eq. (2) yields an estimated primary reflector diameter of $28 \mathrm{~cm}(11 \mathrm{in.})$. The 


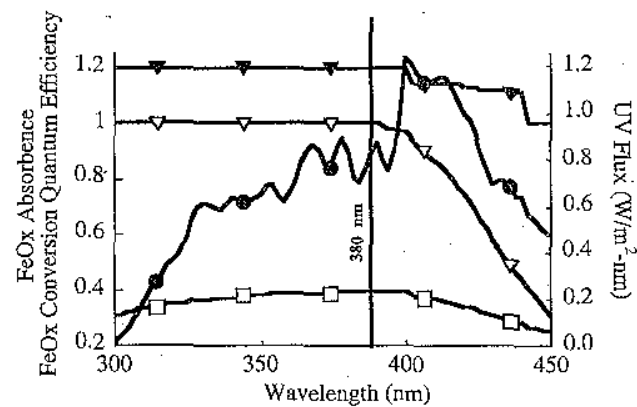

Fig. 6 (J) Ferrioxalate absorbance spectrum and (G) conversion quantum efficiency is compared to (P) solar and (S) Xe lamp spectra for 300 $\leq \lambda \leq 450$

24 in. primary reflector that was employed appeared to be sufficient to provide the minimum required UV flux. As a result of a mismatch between the shape of the primary and secondary reflectors, a fully recollimated beam was not obtainable. The beam input angle ranged from $0 \mathrm{deg}$ to $10 \mathrm{deg}$. However, due to irregularities in the parabolic surface of the primary reflector, only the inner $17 \mathrm{in}$. diameter was effective for sunlight collection.

UV Flux Determination. The input UV flux was measured to determine relative quantum efficiencies for the oxidation of $4 \mathrm{CP}$ and as a basis for comparing the performance of the reactor using artificial and solar light. The absorbance spectrum for ferrioxalate is shown in Fig. 6 and compared to the solar and Xe arc lamp output spectra. As can be seen, the FeOx solution may be absorbed at wavelengths above $380 \mathrm{~nm}$. When the flux at each wavelength was weighted by the respective absorbance of the FeOx solution and the conversion quantum efficiency, it was estimated that only 43 percent and 58 percent of the measured flux can be attributed to the useful wavelengths for the solar and Xe arc lamp sources, respectively (Calvert and Pitts, 1966). Thus, the absorbed UV fluxes for the indoor and outdoor experiments were estimated to be $10 \pm 1$ and $37 \pm 1 \mu \mathrm{E} \mathrm{L}^{-1}$ $\min ^{-1}$, respectively. It should also be noted that the solar flux measurements were made at 12:00 hours when the solar flux was about 90 percent of its peak. The quantum efficiency was calculated using an initial rate evaluated with the first hour sample irradiated between 10:00 and 11:00 hours when the solar flux was at 65-85 percent of its peak. An estimated value of $30 \pm 5 \mu \mathrm{EL}^{-1} \min ^{-1}$ was used to calculate the relative quantum efficiency for the solar irradiation.

The estimated (from data) maximum input UV solar flux of $170 \mu \mathrm{E} \mathrm{min}$ min $^{-1}$ is -14 percent of the theoretical flux available and about $20-40$ percent of the predicted UV input flux after losses. This collection/coupling efficiency is 2.5 to 5 times lower than the empirically estimated efficiency of 35 percent of theoretical. The discrepancy may be due to lower reflection efficiencies for the primary and secondary reflectors and/or a lower coupling efficiency than predicted. The lower input UV flux also resulted in slower reaction rates than were predicted (vide supra).

4-Chlorophenol Oxidations. The photocatalytic surface area plays two important roles in this reactor configuration. The photocatalytic surface area-to-reactor volume ratio determines whether the reaction system is in a mass transport limited or a reaction rate limited regime, assuming the system is not limited by the input light flux. If the system were mass transport limited, an increase in the photocatalytic surface area-to-reactor volume ratio would enhance the observed reaction rates. Given that the thickness of the catalyst coating $(6.0 \mu \mathrm{m})$ and its high porosity, that the characteristic time for diffusion of 4-chlorophenol from the outer edge of the $\mathrm{TiO}_{2}$ coating to the quartz fiber core is approximately $0.04 \mathrm{~s}$; this time can be compared to the half- lives (Table 1) for reaction which ranged from three to five hours. Furthermore, diffusion through the electrical double layer (with a characteristic length of $50 \mathrm{~nm}$ ) of an individual particle will occur within a microsecond time frame. Thus, mass transport is not a limiting factor in this reactor configuration since the bulk fluid is well mixed and the characteristic times for diffusion are short compared to the characteristic chemical reaction times.

In addition, the absorbed light intensity-to-photocatalytic surface area ratio can affect the quantum efficiency. Preyious studies have shown an inverse relationship between the absorbed light flux and the quantum efficiency (Albery et al., 1985; D'Oliveira et al., 1990; A1-Sayyed et al., 1991; Kormann et al., 1991; Ollis, 1991; Ollis, 1991; Mills and Hoffmann, 1993; Peill and Hoffmann, 1996). In illuminated semiconductor photocatalysts, the photogenerated electron-hole pair density increases with an increase in the absorbed light intensity. As a result, at a high absorbed light intensity, the rate of electron-hole recombination is increased relative to interfacial charge transfer. This leads to a lower relative quantum efficiency.

The reaction rate data for the OFR1 and OFR2 reactors suggest that the observed photochemical reaction rates are not mass transport limited. The photocatalytic surface area-to-reactor volume ratio of the OFR2 is about 65 percent that of the OFR1. However, a higher initial reaction rate for the OFR2 outdoor oxidation is observed despite a similar absorbed light intensity compared to the OFR1 oxidation. Other studies have reported similar findings for slurry-phase reactors (Pruden and Ollis, 1983; Matthews, 1988; Turchi and Ollis, 1988; Ollis et al, 1989). In contrast, mass transport effects in fixed-bed photocatalytic reactor systems appear to be a function of the reactor design and reaction parameters such as distribution of the photocatalyst within the reaction volume, the radiation field with respect to the exposed photocatalyst membrane, pollutant concentration, and reaction solution flow rate, (Matthews, 1987; Turchi and Ollis, 1988; Sabate et al., 1991, 1992).

Increasing the coated-fiber number density decreases the relative incident light intensity to which to the photocatalyst is exposed for a given input light intensity. The fiber length should equal but not exceed the propagation length of light in the coated fiber to maximize the input photon utilization. The fiber number, fiber number-densities, and fiber lengths for the OFR1 and OFR2 were 72 and 573,92 and 113 fibers $-\mathrm{cm}^{-2}$, and 0.20 and $0.30 \mathrm{~m}$, respectively. These dimensions resulted in estimated photocatalytic surface areas of 4.4 and $63.6 \mathrm{~m}^{2}$, respectively. In Table 1 the absorbed light intensity normalized by the photocatalytic surface area is compared to the observed relative quantum efficiencies. An inverse correlation is evident between the normalized $I_{\mathrm{abs}}$ and relative quantum efficiency. This confirms our previous findings that higher reaction rates can be achieved using the same power input (i.e., higher quantum efficiencies by maximizing the fiber number density (Peill and Hoffmann, 1996)).

In this system, oxygen sparging $\left(2 \mathrm{ml} \mathrm{min}^{-1}\right)$ serves to mix the reaction solution and to act as the electron acceptor. Mixing of the reaction solution may be necessary to minimize mass transport effects and to enhance the sphere of influence of the activated photocatalytic bundle to treat a volume larger than the bundle volume. In an activated photocatalyst particle, surfacebound $\cdot \mathrm{OH}$ radicals are produced by the oxidation of water by valence band holes. In order to maintain charge neutrality concurrent reduction of surface-bound species via conduction band electrons must occur. In an aerated system, oxygen is reduced and forms superoxide and/or hydroperoxyl radicals. These species can be further reduced to form hydroxyl radicals. In the absence of oxygen or an alternative oxidant, charge neutrality cannot be maintained and photocatalytic activity is inhibited as the photogenerated holes, $h_{v b}^{+}$, and electrons, $e_{c b}^{-}$, recombine. In any practical photocatalytic reaction system, oxygen/ 
air should be present at sufficient levels so as not to be ratelimiting. In the case of the treatment of subsurface environments, the addition of oxygen/air may be required.

In conclusion, a solar-powered prototype OFR for the remediation of contaminated wastestreams was successfully designed and tested. Photoefficiencies with sunlight are comparable to that achieved with a Xe-arc source. In addition, a lower $a b-$ sorbed light intensity-to-photocatalytic surface area ratio is shown to result in a corresponding increase in the relative quantum efficiencies. These results indicate that the OFR configuration may be useful in the passive decontamination of groundwater, underground storage tanks, or other sites where UV radiation is not accessible. Developmental issues that must be addressed before practical in situ application of an OFR system is possible include scale-up and distribution of the fibers throughout the treatment volume, protection of the fibers from breakage, coating lifetime and durability, control of flow through the activated bundle, filtration of particulates and other interfering species such as humic substances present in groundwater that scavenge $\cdot \mathrm{OH}$, enhanced of the photochemical quantum efficiencies, sufficient residence times, mixing, and oxygenation (aqueous phase) or humidification (gas phase).

\section{Acknowledgments}

We are grateful to ARPA and ONR (NAV 5 HFMN N000149J1901) for financial support and to Tim Wu, Janet Kesselman, Scot T. Martin, and Wonyong Choi for scientific support. We would also like to thank $3 \mathrm{M}$ and Degussa for their donations of the optical fiber samples and the P25 photocatalyst, respectively.

\section{References}

Al-Ekabi, H., Safarzadey-Amiri, A., Sifton, W., and Story, J., 1991, " Advanced Technology for Water Purification by Heterogeneous Photocatalysis," Intl. J Environ. Pollut., Vol. 1, pp. 125-136.

Al-Ekabi, H., and Serpone, N., 1988, "Kinetic Studies in Heterogeneous Photocatalysis. 1. Photocatalytic Degradation of Chlorinated Phenols in Aerated Aqueous Solutions over $\mathrm{TiO}_{2}$ Supported on a Glass Matrix," J. Phys. Chem., Vol, 92 pp. 5726-5731.

Al-Sayyed, G., D'Oliveira, J. C., and Pichat, P., 1991, "Semiconductor-Sensitized Photodegradation of 4-Chlorophenol in Water," J. Photochem. Photobiol. A: Chem., Vol. 58, pp. 99-114.

Al-Sayyed, G., Doliveira, J. C., and Pichat, P., 1991, "Semiconductor-Sensitized Photodegradation of 4-Chlorophenol in Water," J. Photochem. Photobiol

A: Chem., Vol. 58, pp. 99-114.

Albery, W. J., Brown, G. T., Darwent, J. R., and Saievariranizad, E., 1985, "Time-Resolved Photoredox Reactions of Colloidal CdS," J. Chem. Soc. Farad. Trans. 1, Vol. 81, pp. 1999-2007.

Barbeni, M., Pramauro, E., and Pelizzetti, E., 1985, "Photodegradation of Pentachlorophenol by Semiconductor Particles," Chemosphere, Vol. 14, p. 195.

Bauer, R., 1994, "Applicability of Solar Irradiation for Photochenical Wastewater Treatment," Chemosphere, Vol. 29, pp. 1225-1233.

Bellobono, I. R., Bonardi, M., Castellano, L., Selli, E., and Righetto, L., 1992 "Photosynthetic Membranes. 23. Degradation of Some Chloroaliphatic Water," J. Photochem: Photobiol. A: Chem, Vol. 67, pp. 109-115.

Bellobono, I. R., Cartara, A., Barni, B., and Gazzotti, A., 1994, "LaboratoryScale and Pilot-Plant-Scale Photodegradation of Chloroaliphatics," Photochem. Photobiol. A.: Chem., Vol. 84, pp. 83-90.

Bockelman, D., Goslich, R., Weichgrebe, D., and Bahnemann, D., 1993 " "Solar Detoxification of Polluted Water: Comparing the Efficiencies of a Parabolic Trough Reactor and a Novel Thin-Film-Fixed-Bed Reactor,"' Photocatalytic Purification and Treatment of Water and Air, D. F. Ollisand and H. Al-Ekabi, eds., Elsevier Amsterdam, pp. $771-776$.

BoIton, J. R., Safarzadeh-Amiri, A., and Cater, S. R., 1995, "The Detoxification of Waste Water Streams Using Solar and Artificial UV Light Sources," Altemative Fuels and the Enviromment, F. S. Sterret, ed., Lewis Publishers, Boca Raton, FL, pp, 187-192.

Calvert, J. G., and Pitts, J. N., 1966, Photochemistry, John Wiley and Sons, New York

Chem. Eng, News, 1985, Vol. 41

Choi, W., and Hoffmann, M. R., 1995; "Photoreductive Mechanism of CC14 Degradation on $\mathrm{TiO}_{2}$ Particles and Effects of Electron Donors," Environ. Sci. Technol., Vol. 29, pp. 1646-1654.

Crittenden, J, C., Zhung, Y., Hand, D. W., Perram, D. L., and Marchand, E. G. 1996, "Solar Detoxification of Fuel-Contaminated Groundwater Using Fixed-Bed Photocatalysts,"' Wat. Environ. Res., Vol. 68, pp. 270-278.
D'Oliveira, J. C., Al-Sayyed, G., and Pichat, P., 1990, "Photodegradation of 2 And 3-Chlorophenol in $\mathrm{TiO}_{2}$ Aqueous Suspensions," Environ. Sci. Technol, Vol. 24, p. 990.

Degussa Corp., 1990, Degussa Technical Bulletin, Vol, 56.

Dibble, L. A., and Riupp, G. B., 1990, "Kinetics of The Gas-Solid Heterogeneous Photocatalytic Oxidation of Trichloroethylene by Near UV Illuminated Titanium Dioxide," Catal. Ltrs., Vol. 4, pp. 345-354.

Dieckmann, M. S., and Gray, K., 1996, "A Comparison of the Degradation of 4-Nitrophenol via Direct and Sensitized Photocatalysis in $\mathrm{TiO}_{2}$ Slurries," Wat. Res., Vol. 30, pp. 1169-I183.

Dieckmann, M. S., Gray, K. A., and Kamat, P. V., 1993, "Photocatalyzed Degradation of Adsorbed Nitrophenolic Compounds on Semiconductor Surfaces," Wat. Sci. Tech., Vol. 25, p. 277.

Fox, M. A., and Dulay, M. T., 1993, "Heterogeneous Photocatalysis," Chem. Rev., Vol. 93, pp. 341-357.

Hoffmann, M. R., Martin, S. T., Choi, W., and Bahnemann, D. W., 1995, "Environmental Applications of Semiconductor Photocatalysis," Chem. Rev., Vol. 95, pp. 69-96.

Hofstadler, K., Bauer, R., Novalic, S., and Heisler, G., 1994, "New Reactor" Design for Photocatalytic Waste-Water Treatment with $\mathrm{TiO}_{2}$, " Environ. Sci. Technol., Vol. 28, pp. 670-674.

Holland, L., 1958, Vacuum Deposition of Thin Films, John Wiley and Sons, New York.

Kormann, C., Bahnemann, D. W., and Hoffmann, M. R., 1991, "Photolysis of Chloroform and Other Organic-Molecules in Aqueous $\mathrm{TiO}_{2}$, , Environ. Sci. Technol., Vol. 25, pp. 494-500.

Matthews, R. W., 1987, "Photooxidation of Organic Impurities in Water Using Thin Films of Titanium Dioxide," J. Phys. Chent., Vol. 91, p. 3328.

Matthews, R. W., 1987, "Solar-Electric Water-Purification Using Photocatalytic Oxidation With $\mathrm{TiO}_{2}$," Solar Energy, Vol. 38, pp. 405-413.

Matthews, R. W., 1988, "Response to the Comment Photocatalytic Reactor Design," J. Phys. Chem., Vol. 92, pp. 6853-6854.

Matthews, R. W., 1990, "Purification of Water With Near-UV Illuminated Suspensions of Titanium Dioxide," Wat. Res., Vol. 24, pp. 653-660.

Mehos, M.S., and Turchi, C.S., 1993, "Field Testing Solar Photocatalytic Detoxification on TCE-Contaminated Groundwater," Environ. Prog., Vol. 12, pp. 194-199.

Miller, R., and Fox, R, 1993, "Treatment of Organic Contaminants in Air by Photocatalytic Oxidation: A Commercialization Perspective," Photocatalytic Purification and Treatment of Water and Air: Trace Metals in the Environment, D. F. Ollis and H. Al-Ekabi, eds,, Elsevier, Amsterdam, pp. 573-578.

Mills, A., Davies, R. H., and Worsley, D., 1993, "Water Purification by Semiconđuctor Photocatalysis," Chem. Soc. Rev., Vol. 22, p. 417.

Mills, G., and Hoffmann, M. R., 1993, "Photocatalytic degradation of Pentachlorophenol on $\mathrm{TiO}_{2}$ particles-Identification of Intermediates and mechanism of reaction," Environ. Sci. Tech, Vol. 27, pp, 1681-1689.

Minero, C., Pelizzetti, E., Malato, S., and Blanco, J., 1993, "Large Solar Plant Photocatalytic Water Decontamination," Chemosphere, Vol. 26, pp. 2103-2119.

Muradov, N. Z., 1994, "Solat Detoxification of Nitroglycerine-Contaminated Water using Immobilized Titania," Solar Energy, Vol. 52, pp. 283-288.

Nimlos, M. R., Jacoby, W. A., Blake, D. M., and Milne, T. A., 1993, "Direct Mass-Spectrometric Studies of the Destruction of Hazardous Wastes. 2," Environ. Sci. Technol, Vol. 27, pp. 732-740.

Ollis, D. F., 1991, Photochemical Conversion and Storage of Solar Energy, E. Pellizzetti and M. Schiavello, eds., Kluwer, Dordrecht, The Netherlands, pp. 593622

Ollis, D. F., and Al-Ekabi, H., 1993, Photocatalytic Purification and Treatment of Water and Air, Elsevier, Amsterdam.

Ollis, D. F., Pelizzetti, E., and Serpone, N., 1989, "Heterogeneous Photocataly" sis in the Environment: Application to Water Purification," Photocatalysis: Fundamentals and Applications, N. Serpone and E. Pelizzetti, eds., John Wiley and Sons, New York, pp. 603-637

Ollis, D. F., Pelizzetti, E., and Serpone, N., 1991, "Photocatalyzed Destruction of Water Contaminants," Environ. Sci. Technol, Vol. 25, pp. 1522-1529.

Pacheco, J. E., Prairie, M. R., and Yellowhorse, L., 1993, "Photocatalytic Destruction of Chlorinated Solvents in Water," ASME JOURNAL OF SOLAR ENERGY ENGINELRING, Vol. 115, pp. 123-129.

Peill, N. J., and Hoffmann, M. R., 1995, "Development and Optimization of a $\mathrm{TiO}_{2}$-Coated Fiber Optic Cable Reactor: Photocatalytic Degradation of 4-Chlorophenol," Environ. Sci. Technol., Vol. 29, pp. 2974-2981.

Peill, N. J., and Hoffmann, M. R., 1996, "Chemical and Physical Characterization of a $\mathrm{TiO}_{2}$-Coated Fiber Optic Cable Reactor," Environ. Sci. Technol., Vol. 30, pp. $2806-2812$.

Pruden, A. L., and Ollis, D. F., 1983, "Photoassisted Heterogeneous Catalysis: The Degradation of Trichloroethylene in Water," J. Catal., Vol. 82, pp. 404417.

Pugh, K, C., Kiserow, D. J., Sullivan, J. M., and Grinstead, J, H., 1995, "Photocatalytic Destruction of Atrazine Using $\mathrm{TiO}_{2}$ Mesh," ACS Industrial and Engineering Chemistry Special Symposium, ACS, Atlanta, GA.

Renner, R., 1996, "Titanium Dioxide Photocatalysis: Treatment Hype or Hope?," Environ. Sci. Technol., Vol. 30, p. 284

Sabate, J., Anderson, M. A., Aguado, M. A., Gimenez, J., Cerveramarch, S., et al,, 1992, "Comparison $\mathrm{Of} \mathrm{TiO}_{2}$ Powder Suspensions and $\mathrm{TiO}_{2}$ Ceramic Membranes Supported on Glass as Photocatalytic Systems in the Reduction of Chromium (VI)," J. Mol. Catal., Vol. 71, pp. 57-68. 
Sabate, J., Anderson, M. A., Kikkawa, H., Edwards, M., and Hill, C. G., 1991, "A Kinetic-Study of the Photocatalytic Degradation of 3-Chlorosalicylic Acid," J. Catal., Vol, 127, pp. 167-177.

Sauer, M. L., and Ollis, D. F., 1994, "Acetone Oxidation in a Photocatalytic Monolith Reactor," J. Catal., Vol, 149, pp. 81-91.

Suzuki, K., 1993, "Photocatalytic Air Purification on $\mathrm{TiO}_{2}$ Coated Honeycomb Support," Photocatalytic Purification and Treatment of Water and Air, D. F. Ollisand and H. Al-Ekabi, eds., Elsevier, Amsterdam, pp. 421-434.

Tseng, J. M, and Huang, C. P., 1991, "Removal of Chlorophenols from Water by Photocatalytic Oxidation," Wat. Sci. Technol., Vol. 23, pp. 377-387

Turchi, C. S., and Ollis, D. F., 1988, "Photocatalytic Reactor Design-An Example of Mass-Transfer Limitations," J. Phys. Chem., Vol. 92, pp. 68526853.

Wilson, E., 1996, Chem. and Engrng. News, Vol. 74, p. 29.

Wyness, P., Klausner, J. F., Goswami, D. Y., and Schanze, K. S., 1994, "Performance of Nonconcentrating Solar Photocatalytic Oxidation Reactors, Part $\mathrm{X}$ : Flat-Plate Configuration," ASME JournaL of Solar ENERGY ENGINEERING, Vol. 116, pp. 2-7.

Wyness, P., Klausner, J. F., Goswami, D. Y., and Schanze, K. S., 1994, "Performance of Nonconcentrating. Solar Photocatalytic Oxidation Reactors, 2," ASME Journal of Solar ENERGy ENGineEring, Vol. 116, pp. 8-13.
Xu, Y. M., Me'nassa, P. E., and Langford, C. H., 1988, "Photodecomposition of Several Chloroaromatics Using a Commercial Prototype Reactor," Chemosphere, Vol. 17, pp. 1971-1976.

Yamazaki-Nishida, S., Nagano, K. J., Phillips, L. A., Cerveramatch, S, and Anderson, M. A., 1993, "Photocatalytic Degradation of 'Trichloroethylene in the Gas-Phase Using Titanium Dioxide Pellets," J. Photochem. Photobiol. A.: Chem., Vol. 70, pp. 95-99.

Zeltner, W. A., Hill, C. G., and Anderson, M. A., 1993, "Supported Títani: For Photodegradation," Chemtech, Vol. 23, pp. 21-28.

Zhang, Y., Crittenden, J. C., Hand, D. W., and Perram, D. L., 1993, "Solar Decontamination of Water with $\mathrm{TiO}_{2}$ Photocatalyst on Silica Based Supports," American Water Works Association Annual Conference, San Antonia, TX,

Zhang, Y., Crittenđen, J. C., Hand, D. W., and Perram, D. L., 1994, "FixedBed Photocatalysts for Solar Decontamination of Water," Environ. Sci. Technol., Vol. 28, pp. 435-442.

Zhang, 'Y., Crittenden, J. C., Hand, D. W., and Perram, D. L., 1996, "Destruction of Organic Compounds in Water Using Supported Photocatalysts," ASME Journal of SOLAR ENERGY ENGINEERING, Vol. 118, pp. 123 129.

\section{The Worlo's Most Active Engineering Site • The World's Most Trusted Engineering Organization}

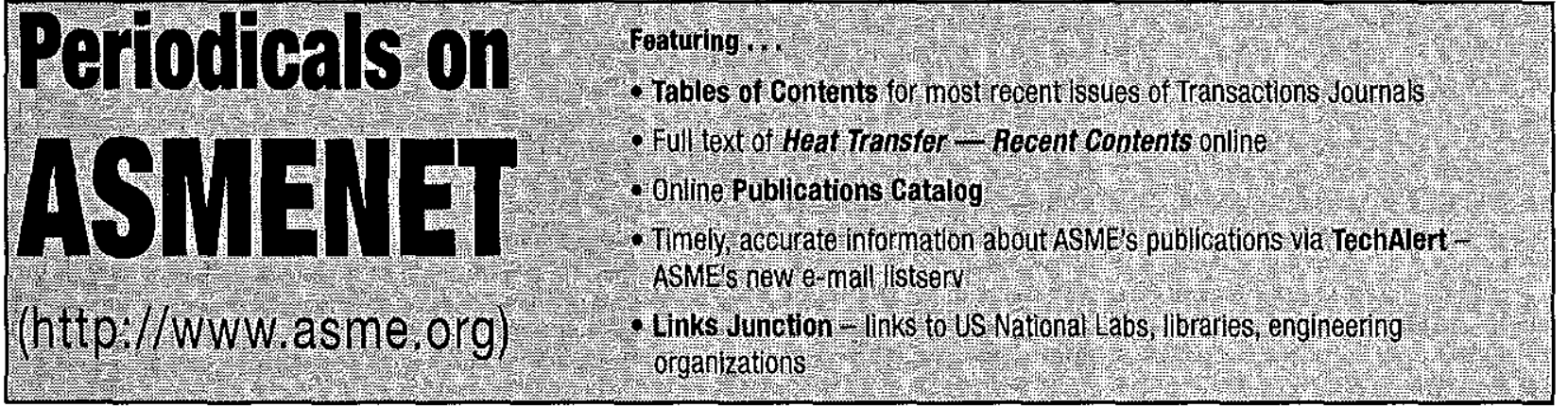

Transactions of the ASME

ASNE Transactions lounals are world edass tepositories of the thest engineoring literature from top researchers in theit fields. Each refereed jounal contans artictes designed to keep teaders abreast of current theory and practice and serve as a permanent technical record of englneering researchand development: 